\title{
Desafios da comunicação pública e científica na promoção da saúde: estudo de caso do portal da UFPR
}

\section{Challenges of public and science communication in health promotion: case study of the UFPR portal}

\author{
Amanda Souza de Miranda ${ }^{1}$, Jéssica Vitória Tokarski Mazeto ${ }^{2}$ \\ 1 Universidade de São Paulo (USP), São Paulo, SP, Brasil; Universidade Federal do Paraná (UFPR), Curitiba, PR, Brasil. ORCID: \\ https://orcid.org/0000-0001-5520-368X \\ 2 Universidade Federal do Paraná (UFPR), Curitiba, PR, Brasil. ORCID: https://orcid.org/0000-0001-8455-9351
}

Autor para correspondência/Mail to: Amanda Souza de Miranda, amandamiranda@ufpr.br

Recebido/Submitted: 30 de novembro de 2020; Aceito/Approved: 02 de fevereiro de 2021

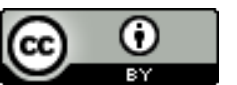

Copyright (C) 2021 Miranda \& Mazeto. Todo o conteúdo da Revista (incluindo-se instruções, política editorial e modelos) está sob uma licença Creative Commons Atribuição 4.0 Internacional. Ao serem publicados por esta Revista, os artigos são de livre uso em ambientes educacionais, de pesquisa e não comerciais, com atribuição de autoria obrigatória. Mais informações em http://revistas.ufpr.br/atoz/about/submissions\#copyrightNotice.

\begin{abstract}
Resumo
Introdução: reflete sobre os conceitos de comunicação pública e divulgação científica a partir da identificação de questões intrínsecas aos setores de comunicação das universidades, responsáveis por produzir informações sobre a pandemia de Covid-19 pensando em disseminá-las amplamente e contribuir com o direito à informação. Método: apresenta um estudo de caso a partir das notícias com maior número de visualizações publicadas no portal da UFPR desde o início da pandemia do novo Coronavírus, com o objetivo de elencar desafios a serem vencidos pela comunicação pública e pela divulgação científica na promoção da saúde. Resultados: parte do pressuposto de que a ciência tem sido uma instituição protagonista no debate público com relação ao combate à pandemia da Covid-19. Analisa um conjunto de 16 conteúdos disseminados pelo portal da UFPR que estiveram entre os mais visualizados entre os meses de março a julho de 2020. Conclusões: na disputa de narrativas, projeta a comunicação das instituições científicas como instância que deve focar suas ações em um papel social: investir em estratégias de divulgação e promoção da saúde e situar-se como mediadora das relações entre ciência e sociedade.
\end{abstract}

Palavras-chave: Comunicação Pública. Divulgação Científica. Promoção da Saúde.

\begin{abstract}
Introduction: it reflects on the concepts of public communication and science communication considering the identification of issues intrinsic to the communication sectors of universities which are responsible for producing information about the pandemic of COVID-19 thinking of disseminating them widely and contribute to the right to information. Method: it presents a case study based on the news with the highest number of views published on the UFPR portal since the beginning of the new coronavirus pandemic, with the aim of listing challenges to be overcome by public communication and scientific dissemination in health promotion. Results: it is based on the assumption that science has been a leading institution in the public debate regarding the fight against the Covid-19 pandemic. It analyzes a set of 16 contents disseminated through the UFPR portal that were among the most viewed from March to July 2020. Conclusion: in the dispute for narratives, it projects the communication of scientific institutions as an instance that should focus its actions on a social role: invest in health promotion and dissemination strategies and position itself as a mediator of the relationship between science and society.
\end{abstract}

Keywords: Public Communication; Scientific communication; Health promotion.

\section{INTRODUÇÃO}

A noção de comunicação pública sempre trouxe desafios importantes a um país que assentou seus modelos comunicativos observando um protagonismo das instituições privadas e grandes empresas de comunicação. Um destes desafios atinge em cheio os novos contextos socioculturais em virtude da pandemia da Covid-19: como dar relevância ao papel das instituições científicas em direção à promoção da saúde?

De acordo com Mcquail (2012, p. 17), público é definido como "aquilo que está aberto, em oposição a fechado, o que está livremente disponível, em vez de privado, em relação ao acesso e à censura, o que é coletivo e comum, não individual e pessoal". Significa dizer que se aborda um aspecto da comunicação que se relaciona diretamente ao direito de qualquer indivíduo de se sentir bem informado em um momento de incertezas, em que tudo o que é regido por interesses privados pode trazer ceticismo e desconfiança, enquanto o que é público pode ser percebido de um modo mais amplo, aberto e igualitário.

A questão-problema do trabalho é: quais os desafios identificados pela unidade de comunicação da UFPR em comunicar a pandemia de Covid-19? O objetivo é refletir sobre os conceitos de comunicação pública e divulgação científica a partir da identificação de questões intrínsecas aos setores de comunicação das universidades, responsáveis por produzir informações sobre a pandemia de Covid-19 pensando em disseminá-las amplamente e contribuir com o direito à informação. Para tanto, faz-se um estudo de caso da produção jornalística da Superintendência de Comunicação e Marketing da Universidade Federal do Paraná (SUCOM/UFPR) no portal da UFPR. 
No quadro teórico, também se considera o conceito de esfera pública habermesiana, entendendo-a como um "espaço argumentativo por meio do qual a sociedade estabelece consensos"(Pereira, 2004). Entende-se que os meios de comunicação partilhavam desse espaço, muitas vezes contribuindo para a racionalização dos debates. Por esta perspectiva, entendemos que a comunicação pública é capaz de ocupar uma posição nesta esfera - e, no que compete às universidades, evidenciar o fazer e o saber científico como fonte de informações qualificadas de promoção da saúde e de elucidação de conflitos causados pela pandemia.

Esta posição, no entanto, também enfrenta uma batalha com as contra narrativas negacionistas, com as fake news e até mesmo com posições político-ideológicas amplamente divulgadas pelo Governo Federal, suscitando um desafio ainda maior: como dar relevância e credibilidade à ciência no debate público, considerando que este está sendo ocupado também por agentes de desinformação?

Nestas reflexões, também se percorre a tradição teórica da divulgação científica, compreendendo-a como espaço de tradução cultural entre o universo da ciência e os saberes, práticas e processos associados ao universo simbólico do popular (Miranda, 2018). Esta tradução não se equivale a uma mera troca de vocabulários, mas à construção de conteúdos potencialmente híbridos, que mesclem aquilo que a ciência produz ao que suas audiências querem e precisam saber.

Por fim, também se utiliza o conceito de promoção da saúde como um dos objetivos de uma divulgação científica aliada à comunicação pública num contexto de crise. Neste sentido, nos alinhamos a Ribeiro (2018, p. 29), segundo a qual a estratégia da promoção da saúde se pauta "na constituição de políticas públicas saudáveis, na criação de ambientes sustentáveis, reorientação dos serviços de saúde, desenvolvimento da capacidade individual dos sujeitos e fortalecimento das ações comunitárias". Entendemos que a comunicação pública e a divulgação científica têm a potencialidade de contribuírem com esses objetivos, caso vençam um conjunto de desafios que permanentemente nos acompanham.

\section{PROCEDIMENTOS METODOLÓGICOS E RESULTADOS}

Para este estudo de caso, implementou-se uma busca com as palavras "corona"e "covid"no publicador Wordpress do portal da UFPR. Verificamos, nos resultados, as notícias com mais de mil acessos, contabilizando um total de 165 publicações. Depois, fizemos novo recorte para redimensionar o corpus, incluindo somente conteúdos com mais de dois mil acessos - ainda assim, um número alto para a análise pretendida: 93. Por fim, fechamos o corpus com as matérias com mais de quatro mil acessos, excluindo aquelas que continham informações de interesse apenas da comunidade interna ou de caráter exclusivamente institucional.

A análise quantitativa foi contrastada com a literatura de referência e também com nossa experiência empírica à frente da comunicação da UFPR e da gestão do portal, considerado um canal direto de comunicação com a sociedade, sem a necessidade de mediação dos órgãos da imprensa. É importante considerar que muitos dos materiais jornalísticos produzidos nos últimos seis meses pelos jornalistas da UFPR repercutiram amplamente na imprensa regional e nacional, mas estamos no atendo, no corpus, apenas as notícias veiculadas originalmente no portal.

Entre os materiais de grande repercussão, está o depoimento dado por uma médica ao portal da UFPR. Perda de olfato e paladar pode permanecer após eliminação da covid-19 ${ }^{1}$ e Médica está sem olfato há 5 meses por causa da covid-19: "É uma mutilação" ${ }^{2}$ são dois exemplos publicados, respectivamente no portal da EBC e no UOL, dois veículos nacionais - um de empresa pública e um da iniciativa privada.

Utilizamos a metodologia da análise de cobertura jornalística (Silva \& Maia, 2011) para dar conta das especificidades do processo de produção de notícia, considerando que este protocolo "comporta o estudo de processos produtivos do passado, bem como de transformações na cobertura ao longo do tempo, sobretudo quando o corpus envolve um recorte temporal extenso". O recorte temporal aqui estabelecido tem em conta o primeiro mês de pandemia (março) e se encerra em julho, quando as notícias sobre Covid-19 ainda ocupavam boa parte das produções divulgadas neste canal.

Trabalhamos com as categorias de notícia, data de publicação, assinatura e número de visualizações, dados incorporados em uma tabela formatada para visualizarmos o conjunto. Os dados geram insights para, a partir da literatura sobre comunicação pública e divulgação científica, construir reflexões sobre os desafios da comunicação da ciência para a promoção da saúde na esfera pública. Este exercício empírico possibilitou um olhar praxiológico para o papel do jornalista e da divulgação científica.

Trabalhamos com um conjunto de 16 notícias ${ }^{3}$, além de termos nos detido também em cinco notas técnicas

\footnotetext{
${ }^{1}$ Perda de olfato e paladar pode permanecer após eliminação da covid-19. [Tarde Nacional]. (2020, agosto 18). Recuperado de https://radios.ebc.com.br/tarde-nacional/2020/08/perda-de-olfato-e-paladar-por-covid-19-pode-permanecer-apos-eliminacao-do

${ }^{2}$ Santiago, A. (2020, agosto 24). Médica está sem olfato há 5 meses por causa da covid-19: "É uma mutilação". Saúde UOL. Recuperado de https://www.uol.com.br/vivabem/noticias/redacao/2020/08/24/medica-esta-sem-olfato-ha-5-meses-por-causa-dacovid-19-e-uma-mutilacao.htm

${ }^{3}$ As notícias analisadas estão reunidas em tabela publicada no link http://bit.ly/2MU2mD4
} 
divulgadas pela comissão científica da UFPR para o acompanhamento da pandemia. Essas notas técnicas, juntas, contabilizaram um total de 21.981 visualizações, um número expressivo e que, de antemão, nos sugere a hipótese de que documentos oficiais assinados por cientistas e amplamente publicizados também têm apelo em contextos de crise.

Destas 16 notícias mais visualizadas, a de maior número de cliques, "Núcleo de Estudos da UFPR divulga mapas sobre Covid-19 no PR e aponta rápida evolução da doença"partiu da sugestão de pauta de um dos professores líderes do projeto. Como foi veiculada logo no início da pandemia, no mês de abril, entende-se que a visibilidade ocorreu por facilitar o caminho entre o público e a informação disponibilizada pelos respectivos órgãos de saúde, traduzindo esses dados em mapas de fácil visualização. Como resumiu Hohlfeldt (2011, p. 232), trata-se de um desafio para as organizações fazer com que a informação que ela detém "possa circular entre seus integrantes e/ou, sobretudo, para fora da organização".

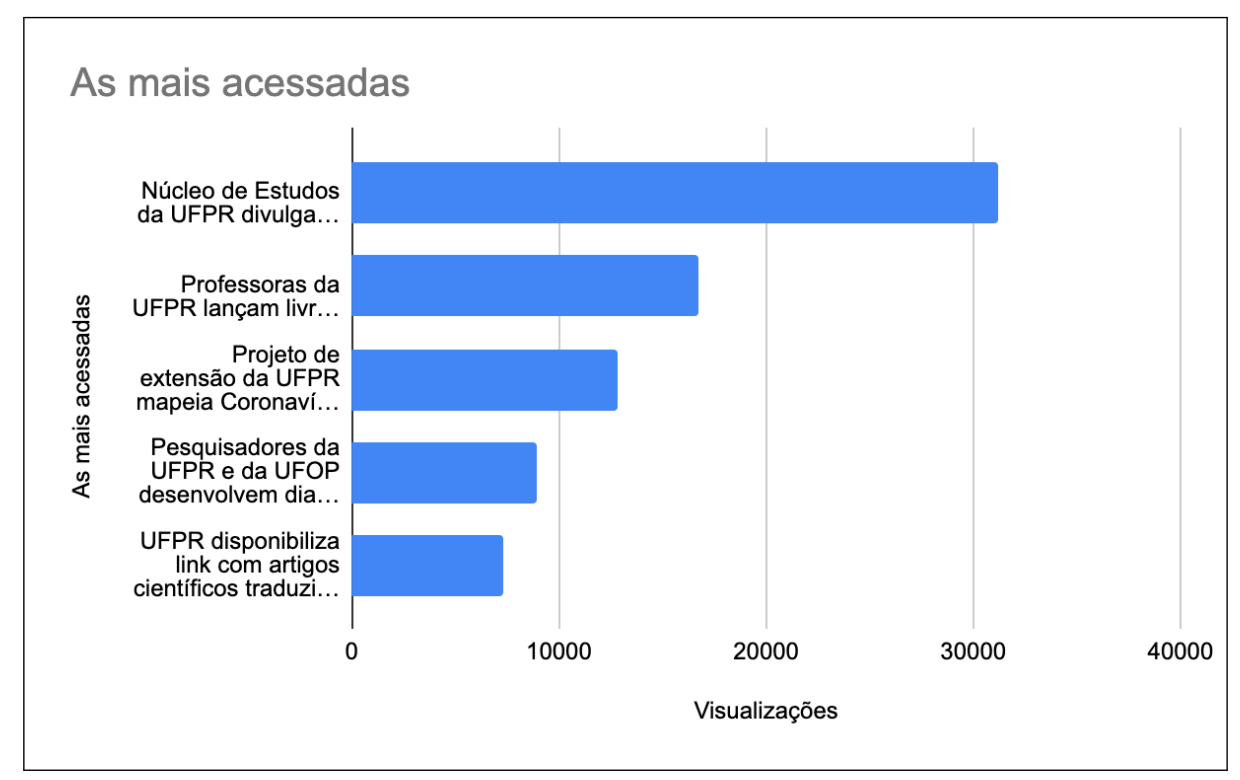

Figura 1. As cinco matérias mais acessadas.

Também destacamos que, dos conteúdos mais visualizados, a maioria (os cinco expostos na Figura 1) circulou no mês de abril, justamente no início da pandemia. Esse dado indica que a comunicação da universidade foi bastante acionada no pico das incertezas, com informações básicas sobre máscaras, estratégias de prevenção ou até com relação a diagnósticos e alternativas e saídas para a crise. Além disso, não desconsideramos o fato de os acessos terem se intensificado em função de um acesso orgânico ao portal por parte da comunidade universitária que buscava informações práticas sobre as rotinas acadêmicas.

Com relação às assinaturas, do ponto de vista jornalístico elas representam a marca autoral, ou seja, quem redigiu o conteúdo está se apresentando ao leitor. Chama a atenção o fato de oito das notícias avaliadas não terem assinatura - o que, em nossa experiência empírica, pode representar tanto uma recusa do redator a se apresentar à audiência, quanto à facilidade do acesso ao publicador com um login genérico, podendo ainda representar um conteúdo produzido em parceria com os pesquisadores (caso das notícias "Perguntas e respostas sobre máscaras caseiras: uso pode ajudar a reduzir transmissão por assintomáticos"e "Professoras da UFPR lançam livro de passatempos sobre mulheres cientistas no combate ao coronavírus; baixe gratuitamente", em que a jornalista responsável precisou apenas adaptar um release enviado por uma das pesquisadoras envolvidas no projeto). Textos assinados, no geral, referem-se a um esforço maior de apuração e produção de notícia, o que nos remete à ideia de que conteúdos mais simples viralizaram em maior número.

Considerando-se a promoção da saúde conforme as definições de Ribeiro (2018), observa-se um alinhamento das publicações com o papel que uma instituição pública deve assumir diante de uma crise na saúde, contribuindo com informação de qualidade que potencialize o bem-estar dos cidadãos. Entre as notícias mais acessadas, observa-se conteúdo de ampla utilidade, a preocupação em disseminar projetos de extensão (que já têm esse papel de se relacionarem diretamente com a sociedade), em explicar a pandemia por meio de modelos estatísticos e em disseminar o conhecimento que geralmente circula apenas intra-pares, caso da notícia "UFPR disponibiliza link com artigos científicos traduzidos sobre Coronavírus".

Este viés de serviço contemplado pelo portal da UFPR destaca-se pelo perfil da equipe que alimenta o portal, formada essencialmente por jornalistas. Durante os meses de pandemia, produtos noticiosos funcionaram como disseminadores de informações de utilidade pública, como na divulgação de estratégias de prevenção, de números e projeções e informações práticas com orientações aos cidadãos. Essa função assumida pelos veículos jornalísticos 
em um momento de crise e de desinformação também foi uma estratégia editorial do site da universidade, o que destaca a relevância de as instituições de ensino manterem jornalistas em seus quadros.

\section{CONCLUSÕES}

Diante dos dados brevemente elencados, situamos três como os principais desafios da comunicação pública e da divulgação científica neste contexto de pandemia: 1) o investimento em conteúdos científicos que promovam e evidenciem esse saber em direção à promoção da saúde; 2) o compromisso dos cientistas com a disseminação deste saber e 3) a construção de uma cultura científica baseada em uma comunicação de interesse público.

Investir em conteúdos com fundamentação e evidências científicas é uma das principais tarefas das universidades, mas também é desafiador ao se pensar na precarização cada vez mais evidente do funcionalismo público e das carreiras associadas à comunicação. É preciso que os órgãos de comunicação sejam unidades com recursos e orçamentos próprios, para que seus conteúdos sejam planejados e distribuídos de modo a fazerem diferença no arsenal de informações acumuladas e dispersas entre fake news e materiais de qualidade duvidosa.

Quanto mais depurados forem esses materiais, mais facilmente eles serão consumidos pela audiência, seja em contato direto com o portal de informação, seja com a mediação de algum veículo jornalístico. Além disso, é notável que quanto mais recursos multimídia eles tiverem, maior será seu potencial de promoção da saúde - áudios, vídeos, imagens e infográficos são notadamente elementos importantes em produtos de divulgação científica e promoção da saúde.

O compromisso dos cientistas com a divulgação também é desafiador, pois acaba sendo uma tarefa muitas vezes incompatível com o fazer científico, exigindo agilidade no compartilhamento de resultados e o desenvolvimento de habilidades em comunicação. Entretanto, a parceria com as unidades de comunicação pode render excelentes resultados, como observamos cotidianamente nos conteúdos com alta taxa de visualização - todos, quase sempre, envolvem uma boa parceria entre o jornalista e o cientista fonte da pauta.

Esta parceria, convém dizer, não surge de forma espontânea e está sujeita a conflitos e tensões, mas isso não impede que seja fomentada a passos mais lentos, com a promoção de uma cultura de dialogia e de parceria entre cientistas e jornalistas. A parceria pode envolver desde cursos de mídia training, oferecido pelos jornalistas, até a revisão científica do conteúdo produzido por jornalistas. Tais iniciativas seriam ainda mais proveitosas se constassem nas políticas de comunicação e documentos oficiais das universidades.

Destaca-se também a importância de os veículos de comunicação oficiais das instituições tornarem-se alimentadores da agenda midiática - seja por meio de parcerias, construção de um relacionamento próximo ou adoção de recursos atrativos para a produção de conteúdo. Apesar de a maioria dos veículos de comunicação de universidades serem abertos à comunidade externa, por se tratar de canais institucionais, entende-se que atraiam mais acessos por parte do público já pertencente a essa comunidade e, portanto, com um conhecimento maior sobre a ciência e a sua relevância. Assim, a estratégia de aproximação da mídia de massa e alimentação de sua agenda é necessária para aproximar ainda mais ciência e sociedade, tornando possível a disseminação de conteúdo científico por meio de veículos populares, com a habilidade de alcançar um maior número de pessoas.

Por fim, é digno de nota evidenciar como um desafio que as pautas de interesse público sejam priorizadas nos conteúdos de divulgação científica neste contexto de pandemia. Nas notícias que coletamos, vimos conteúdos que geram engajamento pois informam aquilo que interessa a diferentes perfis de audiência. É imperativo que as instituições científicas tenham o compromisso de difundirem seu conhecimento contribuindo com o direito universal à informação. 


\section{REFERÊNCIAS}

Hohlfeldt, A. (2011). Comunicação pública: os diferentes sentidos do interesse público. In Comunicação pública, sociedade e cidadania (p. 229-241). São Caetano do Sul: Difusão.

Mcquail, D. (2012). Atuação da mídia: comunicação de massa e interesse público. Porto Alegre: Penso Editora.

Miranda, A. S. (2018). Narrativas híbridas do científico e do popular no jornalismo especializado em saúde (Tese de Doutorado). Universidade Federal de Santa Catarina, Florianópolis, SC, Brasil.

Pereira, M. V. (2004). A espetacularização da política no cidade viva (Dissertação de Mestrado). Universidade Federal do Rio Grande do Sul, Porto Alegre, RS, Brasil.

Ribeiro, M. G. F. (2018). Divulgação científica e promoção da saúde: a interação do agente de controle de endemias com a população de rocha miranda (Dissertação de Mestrado). Fundação Oswaldo Cruz, Casa de Oswaldo Cruz, Rio de Janeiro, RJ, Brasil.

Silva, G., \& Maia, F. D. (2011). Análise de cobertura jornalística: um protocolo metodológico. Rumores, 5(10), $18-36$.

Como citar este artigo (APA):

Miranda, A. S. \& Mazeto, J. V. T. (2021). Desafios da comunicação pública e científica na promoção da saúde: estudo de caso do portal da UFPR. AtoZ: novas práticas em informação e conhecimento, 10(1), 113 - 117. Recuperado de: http://dx.doi.org/10.5380/ atoz.v10i1.77961 